LA W RENCE LIVERMORE NATIONAL LABORATORY

A. Tompson, M. Zavarin

July 25, 2012 
This document was prepared as an account of work sponsored by an agency of the United States government. Neither the United States government nor Lawrence Livermore National Security, LLC, nor any of their employees makes any warranty, expressed or implied, or assumes any legal liability or responsibility for the accuracy, completeness, or usefulness of any information, apparatus, product, or process disclosed, or represents that its use would not infringe privately owned rights. Reference herein to any specific commercial product, process, or service by trade name, trademark, manufacturer, or otherwise does not necessarily constitute or imply its endorsement, recommendation, or favoring by the United States government or Lawrence Livermore National Security, LLC. The views and opinions of authors expressed herein do not necessarily state or reflect those of the United States government or Lawrence Livermore National Security, LLC, and shall not be used for advertising or product endorsement purposes.

This work performed under the auspices of the U.S. Department of Energy by Lawrence Livermore National Laboratory under Contract DE-AC52-07NA27344. 


\section{APPENDIX C: \\ HYDROLOGIC SOURCE TERM SCREENING AND DISTRIBUTION}

\section{A. F. B. Tompson and M. Zavarin, Lawrence Livermore National Laboratory}

\section{C.1. Objectives}

The objectives of this Appendix are to

- Briefly review the definition and nature of the Hydrologic Source Term (HST) and the steps used to develop models of HST behavior for use in larger scale (CAU) models (these are described more thoroughly in the original Yucca Flat Hydrologic Source Term documents of Carle et al., 2008; McNab, 2008; Pawloski, et al., 2008; and Tompson, et al., 2008), and

- Provide additional details and adjustments of several steps in this process that have evolved since the release of the original Yucca Flat HST documents, specifically with respect to the Hydrologic Screening process for identifying the most important radionuclides for inclusion in CAU models.

\section{C.2. Background}

Briefly stated, the Hydrologic Source Term represents the transient release of residual radioactivity into groundwater from former underground nuclear tests. An HST model seeks to quantitatively calculate these releases from mathematical representations of the release processes and physical and chemical data and information related to the test and the altered test environment.

In general, the development of an HST model requires:

- A phenomenological understanding of underground detonation effects and their role in altering the physical and chemical environment surrounding a test location;

- An estimate of the abundance, physical form, and spatial distribution of radioactivity the radiologic source term (or RST) - in the post-test environment; and

- Consideration of complex mechanisms and processes that serve to transfer radioactive compounds into groundwater or to moisture in the vadose zone as a result of (i) the immediate impacts of the detonation, (ii) residual transient effects lingering after a detonation, and (iii) ambient, longer-term processes occurring well after a detonation.

Simplified representations of the HST model are required for use in populating individual source regions in larger scale models of groundwater flow and contaminant transport within the entire Yucca Flat/Climax Mine CAU. By necessity, such models must abstract and generalize many of the complicated release mechanisms over the large numbers of tests encountered in the CAU. Although detailed models of the HST for certain tests have and continue to be developed in order to develop insights into these mechanisms, they cannot be developed for every test in every CAU.

As summarized in Pawloski et al. (2008) and USDOE (2000), 659 underground nuclear tests were conducted in the Yucca Flat/Climax Mine CAU, 656 in Yucca Flat proper, and 3 in the Climax Mine stock just to its north. These tests were associated with 747 unique nuclear 
detonations with announced yields or yield ranges (USDOE, 2000), reflecting the fact that some tests included multiple detonations. Of these, 170 were considered "saturated" zone detonations (conducted below or within $100 \mathrm{~m}$ of the static water level), while the remaining 577 were considered "unsaturated" zone detonations.

\section{C.2.1. Phenomenology}

An underground nuclear explosion will release an immense amount of thermal and mechanical energy (Germain and Kahn, 1968; Borg et al., 1976; OTA 1989; IAEA, 1998a, b, c). The explosion will produce high temperatures and pressures in the geologic materials surrounding the test location (or, working point, WP) and generate a compressive shock wave that moves radially away from it. Vaporization and compression of the geologic media (including water) will generate and expand an open, approximately spherical cavity volume centered at the WP (Figure C.1). The cavity size (or radius) will reach a maximum approximately 500 milliseconds after detonation. The maximum radius of the cavity can be estimated as a function of the energy (yield) of the explosion, its depth of burial, and the strength of the overlying geologic media (Borg, et al., 1976).

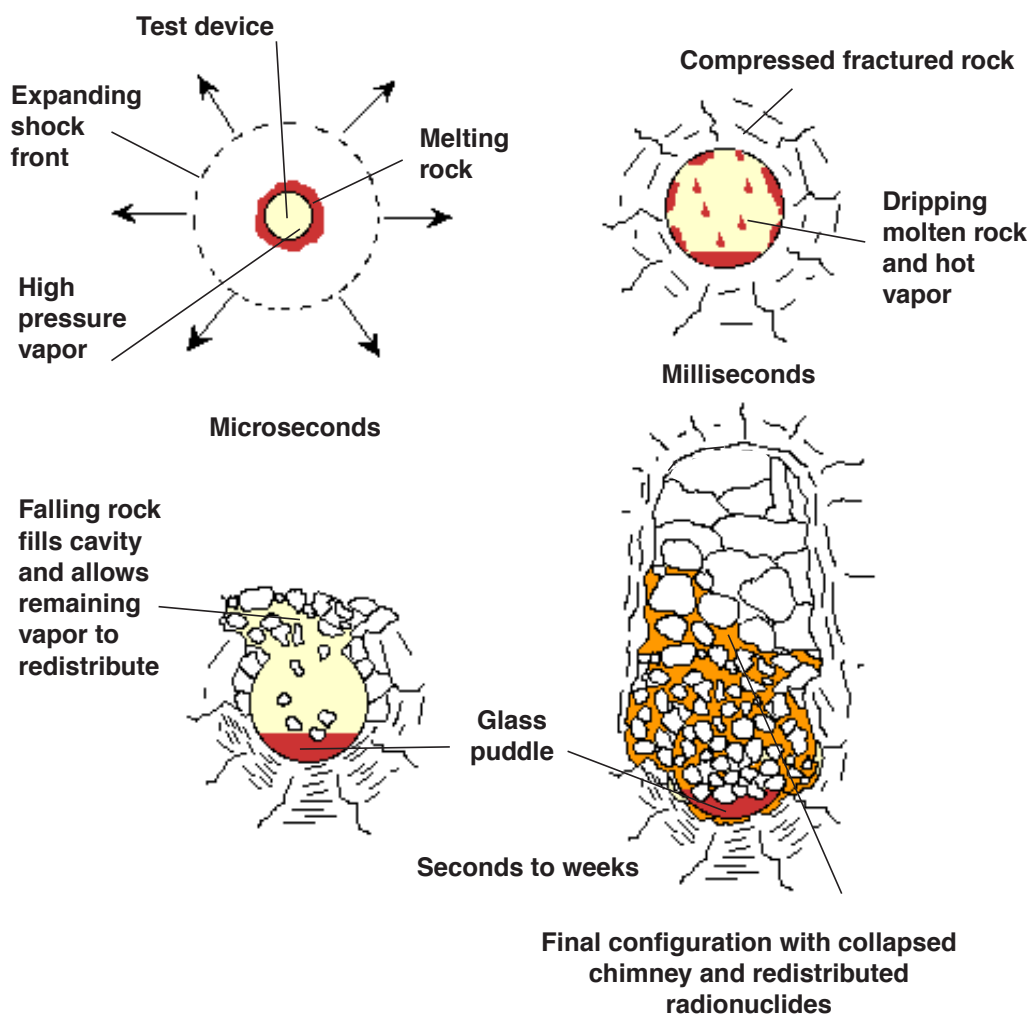

Figure C.1 Phenomenology of an underground nuclear explosion showing accretion of melt glass, redistribution of more volatile radionuclides, initially as gases, later as condensates, and collapse of the chimney. 
During cavity growth, the temperature and pressure of the gas inside will decrease. Components of the gas will condense in an order determined by their relative vapor pressures. First among these are the rock and heavier radionuclide isotopes that, along with molten rock lining the cavity walls, tend to accumulate into a melt glass puddle at the bottom of the cavity. The remaining gases include high-pressure steam, air, and lighter radionuclide isotopes, which condense as final temperature and pressure conditions reestablish in the cavity before collapse.

The shock wave and cavity expansion will serve to crush, fracture, compress, or otherwise alter intact rock that extends beyond the cavity wall and high gas pressures will maintain an open cavity volume. Post-test observations often reveal that a crush zone of permanently pulverized and compressed rock is formed in a zone extending radially away from the cavity wall, beyond which the materials may be compressed, but not otherwise broken or fractured, for some additional radial distance. Hydrofractures outside the cavity region can form when cavity pressure is high. Liquid interstitial water in the rock next to the cavity may also boil, if close to the wall, but will otherwise undergo compression along with the bulk rock surrounding the cavity.

Within minutes to days after detonation, the rock overlying the cavity collapses into the cavity and creates a rubblized column or chimney that may extend to the ground surface where a crater is formed. The collapsed material will have altered physical properties and a variable degree of saturation dependent on pre-collapse conditions. Depending on the timing of collapse, rubble may become dispersed in the melt glass if the glass is still liquid, or remain fairly well intact if it has become more solidified.

For tests detonated below the water table, groundwater in the rock adjacent to the cavity will be pressurized, or compressed, as a result of the explosion and cavity expansion processes and will otherwise return to the cavity as saturation levels in the collapsed material dictate. Pressure dissipation can lead to localized groundwater mounding effects near the explosion site that usually relax over time (Knox et al., 1965; Borg et al., 1976; Burkhard and Rambo 1991; Wolfsberg et al., 2006; Halford et al., 2005; Tompson, et al., 2008). These effects, when limited in extent, were not seen to produce significant enhanced radionuclide migration away from test cavities (Tompson, et al., 2008). However, more extensive pressurization effects may develop from the impacts of multiple tests conducted in close proximity or from broader overburden subsidence effects associated with testing (Vincent et al., 2003). Depending on larger scale geological conditions, these effects may produce possibilities for enhanced radionuclide migration away from test cavities.

High residual temperatures associated with the detonation will be manifested in the melt glass and neighboring media and can last many years (Carle et al., 2003). Returning groundwater will serve to quench some of the higher temperatures and may convect heat away in buoyancy-driven flow to the extent permeability conditions allow (e.g., Pawloski et al., 2001).

For tests detonated above the water table, or for tests whose mechanical impacts extend to areas above the water table, static interstitial moisture or other perched zones of water above the water table may become mobile as a result of altered moisture retention characteristics in the formation. In addition, due to a lack of returning groundwater to a previously unsaturated setting, cooling will be limited to thermal conductive processes only (e.g., without the contribution of groundwater convection). Circulation of cavity gases may occur in the chimney of an unsaturated test and possibly extend to the ground surface. 


\section{C.2.2. Altered Zones}

The hydrodynamic and mechanical impacts from the nuclear explosion produce permanently altered zones such as cavity, nuclear melt glass, crush, compressed, and rubblized collapse chimney zones. The geometries of these zones are dependent on explosion phenomenology, rock type, saturation, and the yield of the test. Transient groundwater flow effects may be created as a result of groundwater condensation and return to the cavity, relaxation of elevated pore water pressures in saturated areas surrounding the cavity, and convective flow processes driven by residual test heat. These effects may be short-lived (months) or longer-lasting (years) depending on the particulars of a given near-field system.

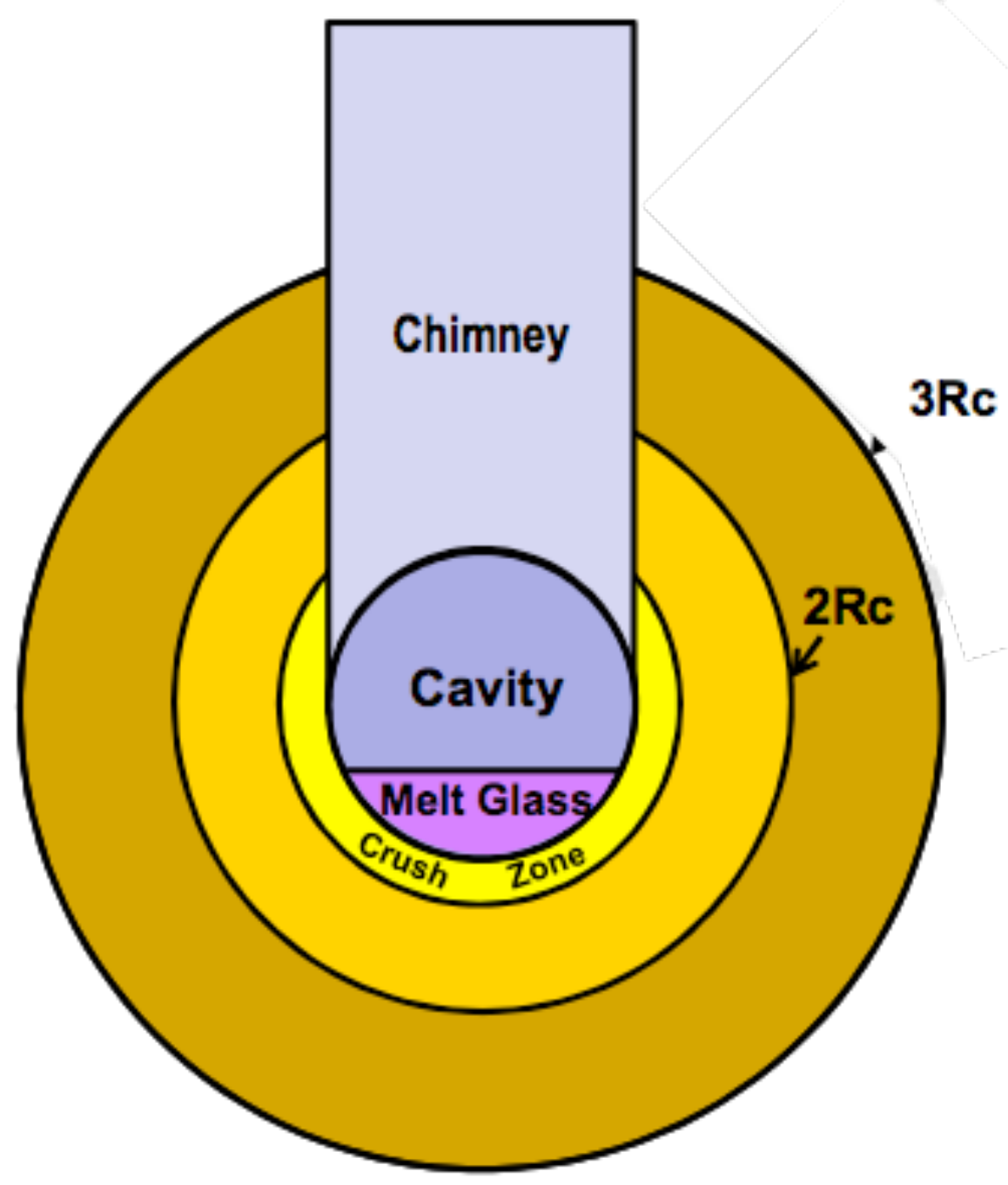

Figure C.2 Schematic diagram for geometry of test-altered zones. All test-altered zones are assumed radially symmetric about the vertical axis.

The general configuration of test-altered zones and properties is largely based on information compiled in OTA (1989) with respect to multiples of cavity radii $\left(\mathrm{R}_{\mathrm{c}}\right)$ :

- Test-enhanced fracture permeability extends to 3 Rc (OTA, 1989). 
- Test-enhanced microfracturing in rocks extends to 2 Rc (OTA, 1989).

- In-situ rock properties do not change beyond 3Rc, except in the chimney (OTA, 1989).

A schematic diagram for geometry of test-altered zones is shown in Figure C.2. Typical concepts used to define the test-altered zones include:

- Cavity - Idealized sphere of radius 1.0 Rc representing the maximum extent of the test cavity. The conceptualized cavity at HST $\mathrm{t}_{0}$ is composed of the melt glass puddle that coalesces at the bottom and the in fallen, rubblized chimney.

- Melt Glass - A zone at the bottom of the cavity where vaporized and melted material accumulates due to gravity. The volume of melt glass can be calculated, and this volume may also contain in-fallen rubble.

- Chimney - An idealized cylinder of rubble that falls into the collapsed cavity void, with a radius set to the cavity radius. The chimney zone may extend to the ground surface or stop before that, dependent on yield of the test and the strength of the overlying rock.

- Crush Zone - A zone within 1.3 Rc that is more intensely fractured or "pulverized" as described in Borg (1973) and Borg et al. (1976). The material in this zone has failed mechanically and permanently lost porosity due to the compressional shock wave.

- Altered Matrix to 2.0 $\mathbf{R}_{\mathbf{c}}$ - Matrix permeability is assumed enhanced to $2.0 \mathrm{Rc}$ as a result of micro fracturing (OTA, 1989).

- Altered Fractures to 3.0 $\mathbf{R}_{\mathbf{c}}$ - Fracture permeability and porosity in in-situ rock is enhanced between 1.0 and $3.0 \mathrm{R}_{\mathrm{c}}$, with increasing fracture permeability closer to the working point (Boardman and Skrove, 1966; OTA, 1989).

\section{C.2.3. Radiologic Source Term}

The Radiologic Source Term (RST) for an underground nuclear test represents the residual, posttest inventory of radioactivity associated with that test. The residual inventory is derived from the original materials in the test device, nuclear reactions connected with the explosion, and activation products created in the geologic medium. Complex dynamic processes occurring in the seconds to weeks after detonation control the initial chemical nature, spatial distribution, and physical partitioning of the RST onto rubble or into melt glass, gas, or water phases found in the cavity and chimney areas surrounding the test.

RST Composition: The composition and magnitude of the RST is generally determined from diagnostic samples of water and rock extracted from these areas and from knowledge of test design. In general, RST data for individual tests are classified. With the exception of a few unclassified RST estimates at specific tests and related unclassified observations of radionuclides in water drawn from scattered wells at the NTS, the most complete unclassified source of radionuclide inventories for tests conducted at the NTS are the aggregate data tabulated in Bowen et al. (2001) and Smith et al. (2003). The Bowen report provides aggregate information on the abundance, or inventory, of 43 specific long-lived radioactive isotopes deemed pertinent to CAU studies (Table C.1). At Yucca Flat, the aggregated inventories are associated with either above-water-table (unsaturated) or below-water-table (saturated) groups of tests. The data are decay corrected to September 23, 1992, the date of the last underground nuclear test. The Bowen 
inventory data include only those isotopes whose half-lives are greater than 10 years, even though shorter-lived radionuclides are produced in nuclear tests. As a result, it does not include some short-lived radionuclides that may otherwise have been measured or observed in groundwater at the NTS.

RST Allocation: In HST and CAU model calculations, the aggregate unclassified RST isotope inventories reported in Bowen et al. (2001) for a given geographic testing area are apportioned to individual tests using a yield-weighting algorithm. The "yield" for each test is either the announced yield (in kt) or the maximum of the announced yield range, as tabulated in USDOE (2000). The yield-weighting process can proceed in one of two ways:

- In the traditional approach, equivalent fractions of the aggregate 1992 inventory are apportioned to equivalent-yield tests as of 1992 . When scaled back to different test $\mathrm{t}_{0}$ times, equivalent-yield tests will have different $\mathrm{t}_{0}$ inventories. This approach has been used in all previous HST analyses, including the YF HST reports (Carle et al., 2008; McNab; 2008; Pawloski, et al., 2008; and Tompson, et al., 2008).

- In a newer approach, developed recently for the HST tunnel models at Rainier Mesa, the aggregate 1992 inventory is apportioned to individual tests in such a way that equivalentyield tests have equivalent inventories at their individual $t_{0}$ times. When corrected to 1992, equivalent yield tests will have different inventories, yet will still sum in the aggregate to the totals cited in Bowen et al. (2001). (At Rainier Mesa his method was deemed important for understanding contributions from multiple closely located tests over time to observations of tunnel effluent concentrations.) The difference between this and the traditional approach is more significant for short-lived radionuclides (such as tritium), yet may be overshadowed by intrinsic uncertainties in the RST itself (below). The newer approach was not considered in the original YF HST reports, and is described here for completeness.

Zero-Yield Tests: To properly apply the aggregate RST inventory associated with Yucca Flat/Climax Mine tests (Bowen et al., 2001), the inventory should be divided among all detonations with announced, non-zero yields. This means that the San Juan, Courser, and Transom test detonations should not appear as unique source release points and that the inventory should be divided among 744 (instead of 747) detonations. These three detonations occurred near other detonations, and contaminant transport paths should merge or be close. This approach is consistent with classification advice, permits allocation of all Bowen inventory, and removes no unique source release points from the model. More specifically, this means that the unsaturated Bowen inventory for the Yucca Flat/Climax Mine underground tests should be divided among 575 detonations (removing San Juan and Courser) and the saturated inventory should be divided among 169 (removing Transom).

Slight-Yield Tests: The announced yields of three tests in Yucca Flat (Pascal A, Pascal B, and Pascal C) were designated in USDOE (2000) as "slight". Recent guidance by DOE now indicates the yield for these three tests should be interpreted for the current purposes as "less than $20 \mathrm{kt}$ ", so that yield-weighted allocations to the RST to these tests should be based upon a maximum yield of $20 \mathrm{kt}$. 
Table C.1: Long-lived radioactive isotopes deemed pertinent to CAU studies as tabulated in Bowen et al. (2001). Potentially relevant RNs to in the models (or sub models) determined in the screening analysis in Section C.3 are shaded appropriately (using the $0.1 \mathrm{MCL}$ limit after $3 \mathrm{H}$ decay).

\begin{tabular}{|c|c|c|c|c|}
\hline \multicolumn{5}{|c|}{ Potentially relevant $\mathrm{RNs}$ at $0.1 \mathrm{MCL}$ limit after $3 \mathrm{H}$ decay } \\
\hline $\begin{array}{c}\text { Bowen } \\
\text { RST }^{1}\end{array}$ & All Tests & $\begin{array}{l}\text { UZ sub } \\
\text { model }\end{array}$ & $\begin{array}{l}\text { SZ sub } \\
\text { model }\end{array}$ & $\begin{array}{c}\text { LCA sub } \\
\text { model }\end{array}$ \\
\hline \multicolumn{5}{|l|}{$3 \mathrm{H}$} \\
\hline \multicolumn{5}{|l|}{$14 \mathrm{C}$} \\
\hline \multicolumn{5}{|l|}{ 26Al } \\
\hline \multicolumn{5}{|l|}{$36 \mathrm{Cl}$} \\
\hline \multicolumn{5}{|l|}{$39 \mathrm{Ar}$} \\
\hline \multicolumn{5}{|l|}{$40 K$} \\
\hline $41 \mathrm{Ca}$ & & & & 2 \\
\hline \multicolumn{5}{|l|}{$59 \mathrm{Ni}$} \\
\hline \multicolumn{5}{|l|}{$63 \mathrm{Ni}$} \\
\hline \multicolumn{5}{|l|}{$85 \mathrm{Kr}$} \\
\hline \multicolumn{5}{|l|}{$90 \mathrm{Sr}$} \\
\hline \multicolumn{5}{|l|}{$93 \mathrm{Zr}$} \\
\hline \multicolumn{5}{|l|}{$93 \mathrm{mNb}$} \\
\hline \multicolumn{5}{|l|}{$94 \mathrm{Nb}$} \\
\hline \multicolumn{5}{|l|}{ 99Tc } \\
\hline \multicolumn{5}{|l|}{$107 \mathrm{Pd}$} \\
\hline \multicolumn{5}{|l|}{$113 \mathrm{mCd}$} \\
\hline \multicolumn{5}{|l|}{$121 \mathrm{mSn}$} \\
\hline \multicolumn{5}{|l|}{$126 \mathrm{Sn}$} \\
\hline \multicolumn{5}{|l|}{1291} \\
\hline \multicolumn{5}{|l|}{$135 \mathrm{Cs}$} \\
\hline \multicolumn{5}{|l|}{$137 \mathrm{Cs}$} \\
\hline \multicolumn{5}{|l|}{$151 \mathrm{Sm}$} \\
\hline 150Eu & & & & \\
\hline $152 \mathrm{Eu}$ & & & & \\
\hline $154 \mathrm{Eu}$ & & & & \\
\hline $166 \mathrm{mHo}$ & & & & \\
\hline 232Th & & & & \\
\hline 2320 & & & & \\
\hline 2330 & & & & \\
\hline $234 U$ & & & & \\
\hline 2350 & & & & \\
\hline 2360 & & & & \\
\hline $238 U$ & & & & \\
\hline $237 \mathrm{~Np}$ & & & & 2 \\
\hline $238 \mathrm{Pu}$ & & & & \\
\hline $239 \mathrm{Pu}$ & & & & \\
\hline $240 \mathrm{Pu}$ & & & & \\
\hline $241 \mathrm{Pu}$ & & & & \\
\hline $242 \mathrm{Pu}$ & & & & \\
\hline $241 \mathrm{Am}$ & & & & \\
\hline 243Am & & & & \\
\hline 1 & Bowen et al. (2 & & & \\
\hline 2 & At the margin o & usion & & \\
\hline red & no published $\mathrm{EF}$ & L (dose eq & & \\
\hline blue & as a gas, no pub & d EPA MCL & equiavlent) & \\
\hline
\end{tabular}

Uncertainty in the RST: Different methodologies have been used for estimating the quantities of nuclides that appear in the Bowen inventory, and there are uncertainty or accuracy limitations associated with each method. The general limitations reported by Bowen et al. (2001) include accuracies for fission products ( $\sim 10$ to $30 \%$ for most); unspent fuel materials ( $\sim 20 \%$ or better); 
fuel activation products $(\sim 50 \%$ or better); residual tritium ( $\sim 300 \%$ or better $)$; and activation products ( $\sim$ a factor of 10$)$. As noted, additional differences from these general results apply in some specific cases. The uncertainties are based upon classified RST estimates for individual tests. They cannot - and should not - be interpreted to represent a relationship between unclassified yield-weighted RSTs and their classified test-specific counterparts. The uncertainties used in unclassified calculations can only be used to evaluate the extent to which RST uncertainty may affect contaminant boundary calculations if classified RSTs were used.

As a rule, any quantifiable uncertainty in the RST should be propagated into the HST, simplified HST, and CAU model calculations. Additional discussion of this concern is included in screening discussion of Section C.3.

Screening of the RST: An HST screening activity was developed to identify a subset of the 43 Bowen radionuclides that are anticipated to have the most significant impact on groundwater contamination - or, in other words, eliminate or exclude radionuclides from the list or 43 that are not expected to significantly contribute to the contaminant boundary calculations in the CAU model. As described in section C.3 below, the screening approach is based upon an analysis of the expected initial aqueous concentrations for Yucca Flat tests and folds together a myriad of parameters and uncertainties in the

- Magnitude of the RST inventories for each radionuclide

- Ranges of exchange volume radii for particular radionuclides (see below),

- $\quad$ Ranges in the melt glass partitioning percentage for pertinent radionuclides, including melt glass release rates, and

- Porosity, saturation, and sorption characteristics of the cavity and chimney host rock.

The screening analysis was conducted for all YF-CAU tests and for subsets of tests located in the Unsaturated Zone (UZ), Saturated Aquifer (SZ), and Lower Carbonate aquifer (LCA) submodels. Specific results are shown in Table 1. Differences arise primarily because specific sorption conditions in the LCA promote higher concentrations and mobilities for some radionuclides that, in turn, increase their regulatory relevancy. Because of the general trend for downward migration of radionuclides, from the $\mathrm{VZ}$ to the $\mathrm{SZ}$ and to the LCA, the structure of these results is consistent with the inclusion of more radionuclides at tests later in the overall progression - in the LCA sub model - than in the SZ and VZ sub models.

\section{C.2.4. Physical Partitioning and Spatial Distribution of the RST}

Melt Glass, Water, Gas, and Rubble: Following an underground nuclear detonation, radionuclides are generally expected to partition into one or more Melt Glass, Water, Gas, or Rubble phases distributed in and about the cavity and altered zones. Their physical partitioning and spatial distribution is governed by thermodynamic properties of the radionuclides, testrelated phenomenological effects, and other conditions in the rock media where the detonation took place. Specifically:

- Melt Glass fractions are concentrated in the bottom half of the cavity and typically include between $95 \%$ and $100 \%$ of the actinides in the RST and significant amounts of all other radionuclides (with the exception of ${ }^{3} \mathrm{H},{ }^{14} \mathrm{C}$, and ${ }^{85} \mathrm{Kr}$ ). 
- Water fractions, initially, contain large fractions of the Tritium inventory and smaller amounts of ${ }^{14} \mathrm{C},{ }^{36} \mathrm{Cl},{ }^{39} \mathrm{Ar},{ }^{85} \mathrm{Kr}$, and ${ }^{129} \mathrm{I}$ that show up in condensed steam.

- Gas fractions include significant fractions of non-condensable species such as ${ }^{14} \mathrm{C},{ }^{39} \mathrm{Ar}$, and ${ }^{85} \mathrm{Kr}$ remaining after steam condensation.

- Rubble fractions include other condensable species that do not fall out with water.

Because most previous HST models focused saturated zone tests, it was common to merge the Water, Gas, and Rubble fractions of the RST into a common aqueous distribution. These concepts are discussed more thoroughly in IAEA (1998a, b, c), the original YF HST reports (Carle et al., 2008; McNab; 2008; Pawloski, et al., 2008; and Tompson, et al., 2008), in the more recent studies of Rose et al. (2011) and Tompson et al. (2011), and in Section C.3.

Exchange Volume: The exchange volume is commonly defined as the volume of rock that encompasses the immediate extent of non-melt glass radioactive contamination following an underground nuclear detonation.

In previous HST modeling efforts, including parts of the original Yucca Flat HST models, the exchange volume was conceptualized as a spherical region centered on the test working point with a radius ranging from 1.5 to 3 cavity radii $\left(\mathrm{R}_{\mathrm{c}}\right)$ - into which all non-melt glass RST radionuclides were homogeneously distributed in available groundwater. This conceptualization was supported by basic phenomenological arguments and limited radionuclide distribution data obtained in several test cavity drill back holes, as well as a desire for parsimony in the overall approach. Because most previous HST models focused saturated zone tests, the merged Water, Gas, and Rubble fractions of the RST were introduced into a common aqueous distribution within the saturated portions of the exchange volume. Depending on the radionuclide, the aqueous species would also be subject to sorption interactions (e.g., aqueous complexation or ion exchange reactions) with the solid phase minerals comprising the rock in the exchange volume.

Recent HST model development activities at Rainier Mesa have attempted to address the concept that radionuclides are actually heterogeneously distributed within an exchange volume, that the exchange volume may be non-spherical, and that the size or extent of an exchange volume can be both variable and radionuclide dependent. Such concepts are supported by

- Additional data available at Rainier Mesa - specifically from the mine-back activities conducted at the Rainier test (U-12b) itself (e.g., Wadman and Richards, 1961; Essington and Forslow, 1971),

- New cavity data obtained at Chancellor (U-19ad) (Rose, et al., 2011), and

- Updated modeling analyses (Carle et al., 2008; Tompson, et al., 2008) that address gas and liquid phase radionuclide migration in unsaturated environments (such as those at Yucca Flat) - whose results imply that broader and more disparate aqueous phase distributions may exist for some radionuclides (say, to 5 cavity radii in the short term) along with more transient, "shifting" exchange volume dimensions.

Exchange Volume Size: As a practical means to address these issues, the recommended approach for specifying the exchange volume size involves the use of a spherical volume whose diameter is drawn from a radionuclide-specific range, inside of which the pertinent radionuclide species are uniformly distributed. This is seen as a reasonable approximation to represent 
differing realities and situations characterized by non-spherical radionuclide distributions, nonuniform radionuclide distributions, and/or radionuclide-specific distributions with (essentially) one degree of freedom to represent uncertainty or test-to-test variability (the Rc multiplier). One of the principal ideas in this simplification is that it will allow for the generation of concentration distributions that are fairly consistent with observations, the phenomenological

conceptualization, and our modeling results. Secondary considerations, such as the inclusion of an explicit chimney to distribute recirculating radionuclides originally in the cavity, can also be considered. Specifically:

(a) To determine the appropriate exchange volume size, the following simple criteria are recommended:

- If a radionuclide partitions into glass at $\geq 90 \%$, its exchange volume range is 1 to $1.5 \mathrm{Rc}$

- If a radionuclide partitions into glass at $<90 \%$ but $>0 \%$, its exchange volume range is 1.5 to $3 \mathrm{Rc}$

- If a radionuclide partitions into glass at $0 \%$, its exchange volume range is 3 to $5 \mathrm{Rc}$

- For Tritium $\left({ }^{3} \mathrm{H}\right)$, an exchange volume range is 1.5 to $3 \mathrm{Rc}$ should be used

- For ${ }^{14} \mathrm{C}$, the above-water table exchange volume range is 3 to $5 \mathrm{Rc}$, or an adjusted range based on additional test-specific or condition specific evidence.

- For Carbonate tests, ${ }^{90} \mathrm{Sr}$ and ${ }^{137} \mathrm{Cs}$ have ranges that are higher than shown in earlier YF HST studies

(b) Uncertainty in exchange volume diameter should be based on a triangular distribution symmetric about the mean of the minimum and maximum diameter exchange volume.

(c) For model grid constraints that limit the exchange volume size to 1.5 or $2.5 \mathrm{Rc}$, utilize $2.5 R c$ in place of $3 R c$.

(d) For transport models based upon particle algorithms, attempt to honor the table limits regardless of grid and material property constraints.

(e) For exchange volumes that cross model boundaries (VZ/SZ or SZ/LCZ), we recommend splitting assignments according to the table.

- Reapportioning mass from one model side into another (as in "breaching" cases in earlier Yucca Flat models) is not recommended

- In cases where the recommended process cannot be followed, explicit recognition of all such instances in a summary table or section with appropriate discussion or justification of process should be followed

(f) For potentially relevant $\mathbf{R N s}$, it is not recommended that any $\mathbf{R N}$ mass identified in the Bowen Inventory for the $\mathrm{CAU}$ be excluded from the model.

- In cases where the recommended process cannot be followed, explicit recognition of all such instances in a summary table or section with appropriate discussion or justification of process should be followed

Recommended ranges of Exchange Volume diameters for the highlighted radionuclides in Table C. 1 are summarized in Table C.2. 
Table C.2: Recommended ranges of Exchange Volume diameters for the highlighted radionuclides in Table C.1. Shaded entries represent changes from previous YF HST report recommendations

\begin{tabular}{|c|c|c|c|c|c|c|}
\hline \multirow[b]{3}{*}{$\mathbf{R N}$} & \multicolumn{6}{|c|}{ Range of Exchange Volume Radii (in terms of Rc) } \\
\hline & \multicolumn{2}{|c|}{ UZ sub model } & \multicolumn{2}{|c|}{ SZ sub model } & \multicolumn{2}{|c|}{ LCA sub model } \\
\hline & EV min & EV max & EV min & $\mathrm{EV} \max$ & EV min & $\mathrm{EV} \max$ \\
\hline $3 \mathrm{H}$ & 1.5 & 3 & 1.5 & 3 & 1.5 & 3 \\
\hline $14 \mathrm{C}$ & 3 & 5 & 1.5 & 3 & 3 & 5 \\
\hline $36 \mathrm{Cl}$ & 1.5 & 3 & 1.5 & 3 & 1.5 & 3 \\
\hline $41 \mathrm{Ca}$ & 1.5 & 3 & 1.5 & 3 & 1.5 & 3 \\
\hline $63 \mathrm{Ni}$ & 1 & 1.5 & 1 & 1.5 & 1 & 1.5 \\
\hline $90 \mathrm{Sr}$ & 1.5 & 3 & 1.5 & 3 & 3 & 5 \\
\hline 99Tc & 1.5 & 3 & 1.5 & 3 & 1.5 & 3 \\
\hline 1291 & 1.5 & 3 & 1.5 & 3 & 1.5 & 3 \\
\hline $135 \mathrm{Cs}$ & 1.5 & 3 & 1.5 & 3 & 1.5 & 3 \\
\hline 137Cs & 1.5 & 3 & 1.5 & 3 & 3 & 5 \\
\hline $235 U$ & 1 & 1.5 & 1 & 1.5 & 1 & 1.5 \\
\hline $238 U$ & 1 & 1.5 & 1 & 1.5 & 1 & 1.5 \\
\hline $237 \mathrm{~Np}$ & 1 & 1.5 & 1 & 1.5 & 1 & 1.5 \\
\hline $238 \mathrm{Pu}$ & 1 & 1.5 & 1 & 1.5 & 1 & 1.5 \\
\hline 239Pu & 1 & 1.5 & 1 & 1.5 & 1 & 1.5 \\
\hline $240 \mathrm{Pu}$ & 1 & 1.5 & 1 & 1.5 & 1 & 1.5 \\
\hline
\end{tabular}

On the Distribution of Non-Glass Radionuclide Inventory in a Model Exchange Volume:

As a practical means to address this process, the following guidelines are provided:

To distribute the non-glass inventory inside an exchange volume for an included radionuclide $(\mathrm{RN})$ :

- Identify RN mass (M) from (a) Bowen et al., (2001), (b) yield-weighted allocation process, and (c) glass partitioning criteria

- Identify appropriate range of Exchange Volume radii from Table C.2

- Assume uniform degree of (significant and increased) altered zone fracturing, unless material is alluvium.

- Assume an effective cavity zone porosity of 0.2 to 0.4 , inclusive of matrix and rubble/fracture portions

- Above the water table, consider non-zero water saturation in altered zone fractures derived from condensed steam derived from pore water originally in cavity rock that was melted.

- $\quad$ Determine concentration $\mathrm{C}=\mathrm{M} / \mathrm{V}$

- Identify eligible water volume (V) inside EV radius: (a) total effective cavity zone pore water $+(b)$ total altered zone fracture water. Include altered zone pore water in alluvium. Exclude altered zone matrix water.

- Assign mass to eligible water volume (V) in EV to ensure constant value of C 
- Below the water table, consider the redistribution of cavity mass for Tritium $\left({ }^{3} \mathrm{H}\right),{ }^{14} \mathrm{C}$, and ${ }^{36} \mathrm{Cl}$ into the chimney zone, but no further than water table

- Above the water table, consider the redistribution of cavity mass for ${ }^{14} \mathrm{C}$ into the chimney zone

\section{C.3. Hydrologic Source Term Screening}

\section{C.3.1. Purpose}

The HST screening activity was developed to identify radionuclides that have a significant impact on groundwater contamination. The screening is intended to identify radionuclides that are likely to significantly contribute to the contaminant boundary calculation and focus CAU transport models on those radionuclides.

\section{C.3.2. Conceptual Model and Basis}

The conceptual model is based on simplified parameterization of the phenomenologic model described above. The screening is based on radionuclide concentrations (and associated MCLs) in the exchange volume prior to advective transport. To ensure that the effect of glass dissolution on radionuclide concentrations is conservatively estimated, the first 100 years of glass dissolution and radionuclide release are included in the initial exchange volume concentration. Thus, the screening is based on the highest plausible radionuclide concentration that may be encountered in the near field.

\section{C.3.3. Approach}

The screening begins with the 43 radionuclides identified by Bowen et al. (2001). Based on the parameter uncertainties defined below, 59,760 Monte Carlo realizations of the initial radionuclide concentration in the exchange volume were run ( 80 realizations per test in Yucca Flat). Based on the concentration of each radionuclide in these realizations, the following screening criteria are applied at the $95 \%$ confidence interval:

1. The radionuclide is predominantly of natural origin ${ }^{1}$

2. The radionuclide concentration is $<0.1$ of its MCL

3. The radionuclide will decay to $<0.1$ of its MCL prior to the decay of tritium to $<0.1$ of its MCL

The $0.1 \mathrm{MCL}$ criterion was used to ensure that additive contribution of radionuclides to risk would remain below a total of $1 \mathrm{MCL}$ at the $95 \%$ confidence interval. Since the prevailing conditions in each of the three CAU sub-models differ significantly in some cases (e.g. \% saturation in unsaturated versus saturated models), the screening is grouped into tests whose working point falls within $3 \mathrm{Rc}$ of each of the three sub-models.

\section{C.3.4. Simplifications}

As described in the following sections, a number of pragmatic simplifications are utilized in support of this analysis. Given the scale of these simplifications, the accuracy of this analysis should be considered accordingly. The screening analysis is not intended to provide an exact

\footnotetext{
${ }^{1}$ The natural origin criterion is not based on a $95 \%$ confidence interval. It is intended to remove ${ }^{40} \mathrm{~K}$ and ${ }^{232} \mathrm{Th}$ from further consideration. However, these radionuclides would also be screened out based on the $<0.1 \mathrm{MCL}$ limit.
} 
initial radiologic composition of the near field at each test. Instead, it is meant to broadly screen for relevance of radionuclides with respect to contaminant boundary calculations. The conservative nature of this analysis ensures that only those radionuclides that pose very little risk are excluded from further analysis. This argument is strengthened by comparing the lists of screened radionuclides to groundwater sampling and analysis data from near field "hot well" samples. Based on this comparison, all radionuclides found to exist above their respective MCLs in "hot wells" were correctly identified as relevant to contaminant boundary calculations. However, the conservative nature of this analysis has also resulted in the inclusion of some radionuclides that have, to date, never been measured above their respective MCLs at the NNSS.

The MCLs were taken directly from $4 \mathrm{mrem} / \mathrm{yr}$ published values of the EPA. However, certain radionuclides included in the Bowen et al. (2001) inventory have no published EPA MCLs. In those cases, dose conversion factors from ICRP Publication 72: Age-dependent Doses to the Members of the Public from Intake of Radionuclides Part 5, Compilation of Ingestion and Inhalation Coefficients was used. These values were taken from a database compilation located in the ResRad code developed jointly by the Department of Energy and U.S. Nuclear Regulatory Commission. The radionuclide for which ICRP dose conversion factors were used were: ${ }^{26} \mathrm{Al}$, ${ }^{40} \mathrm{~K},{ }^{41} \mathrm{Ca},{ }^{93 \mathrm{~m}} \mathrm{Nb},{ }^{107} \mathrm{Pd},{ }^{113 \mathrm{~m}} \mathrm{Cd},{ }^{121 \mathrm{~m}} \mathrm{Sn},{ }^{126} \mathrm{Sn},{ }^{150} \mathrm{Eu}$, and ${ }^{166 \mathrm{~m}} \mathrm{Ho}$. For each of these radionuclides, the $4 \mathrm{mrem} / \mathrm{yr}$ MCL was based on 2L/day consumption rate and 365.25 days/year. Two

radionuclides, ${ }^{39} \mathrm{Ar}$ and ${ }^{85} \mathrm{Kr}$, had no reported MCL. Both radionuclides are gases and there is no reasonable pathway to ingestion (i.e. both radionuclides rapidly degas from water).

\section{C.3.5. Parameter Distributions and Basis Used in HST Screening}

RST: The RST for each test was based on yield weighting of the Bowen et al. (2001) inventory using the traditional approach. The difference in radionuclide distribution patterns using the traditional and new approach for short-lived radionuclides is not appreciably greater that the RST uncertainty already identified in Bowen et al. (2001) (Figure C.3). Thus, the choice of yield weighting methodology will not affect these analyses. Bowen et al. (2001) segregated Yucca Flat tests into those considered "saturated" and "unsaturated". The RST for each test accounted for this categorization.

Uncertainty in the RST followed the methodology identified in Rainier Mesa HST analysis and based on the uncertainties identified in Bowen et al. (2001). Uncertainty was assumed to follow a log-triangular form. The applied uncertainty was geometric rather than arithmetic because (1) an arithmetic application would result in negative RSTs in many cases and (2) discussions with weapons testing radiochemists indicated that a geometric distribution was phenomenologically more appropriate. A triangular distribution was employed because it established the geometric mean concentration as most likely. In the context of the accumulated uncertainties from all parameters, RM HST screening calculations indicated that uniform or triangular RST distributions yield the same set of dominant radionuclides.

Cavity Radius: Cavity radius was calculated based on (Pawloski, 1999):

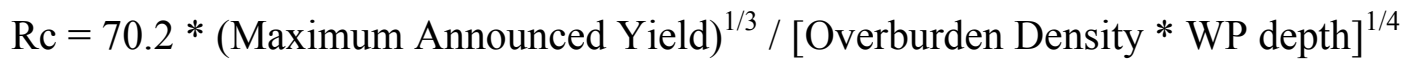

Values were taken directly from Pawloski test categorization effort (Pawloski et al., 2005). Uncertainty in the cavity radius was not addressed. 

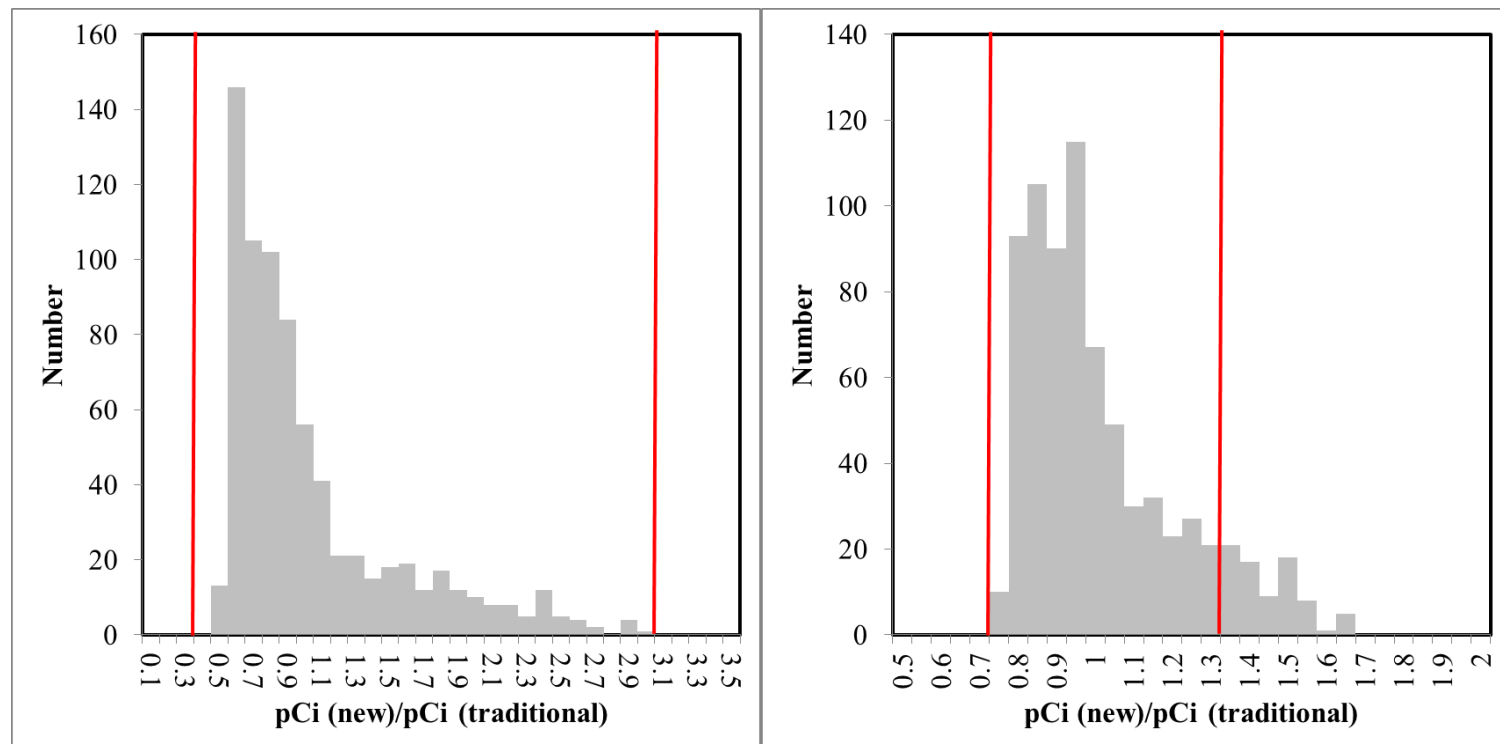

Figure C.3. Comparison of (A) $3 \mathrm{H}$ and (B) $90 \mathrm{Sr}$ RSTs at $\mathrm{t}_{0}$ for all Yucca Flat tests using the new versus traditional yield weighting methods. Red lines identify RST uncertainty range identified in Bowen et al. (2001).

Exchange Volume Radius: The exchange volume radius was radionuclide-specific and fell into one of three categories: 1-1.5 Rc, 1.5-3 Rc, or 3-5 Rc. The categorization of radionuclides into these three bins was based on observations at Rainier Mesa and the known volatility of each radionuclide and its precursors. For example, plutonium is a refractory element that is deposited primarily in the nuclear melt glass. Its exchange volume radius was estimated to be between 1 and $1.5 \mathrm{Rc}($ avg. $=1.25)$. Noble gases $\left(\right.$ e.g. $\left.{ }^{85} \mathrm{Kr}\right)$ or ${ }^{14} \mathrm{CO}_{2}$ are likely to migrate away from the cavity as gases at early time. Thus, their exchange volume radius will be significantly larger (3 to $5 \mathrm{Rc}(\mathrm{avg} .=4))$. However, as was shown in the Rainier Mesa HST calculations, the scale of the exchange volume for gaseous radionuclides is spatially heterogeneous and time-dependent. Thus, the 3-5 Rc range should be considered an approximate snapshot of the gaseous radionuclide exchange volume at early time.

Glass Partitioning: Each radionuclide was partitioned between nuclear melt glass and the water in the exchange volume. Partitioning was based on IAEA (1998a) recommendations and adjusted, when appropriate, based on direct evidence from the NNSS. The direct evidence came primarily from two sources: The Rainier Mesa HST analysis (Tompson, et al., 2011) and the summary of radionuclide partitioning based on sampling efforts at the Chancellor site (Rose et al., 2011). Uncertainty in the glass partitioning is not well known. However, comparison of IAEA (1998a) recommendations, combined with radionuclide distribution information from the Rainier and Chancellor tests, provides a qualitative representation of partitioning uncertainty. All glass partitioning uncertainty is based on a triangular distribution. For each Monte Carlo iteration, partitioning into the other materials (gas, water, rubble) was adjusted based on the fraction assigned to glass partitioning. Partitioning falls into the following categories:

- All gases $\left({ }^{3} \mathrm{H},{ }^{14} \mathrm{C},{ }^{85} \mathrm{Kr},{ }^{39} \mathrm{Ar}\right): 0 \%$ in glass

- All refractory radionuclides identified by IAEA as $95 \%$ or $98 \%$ in the glass $\left({ }^{26} \mathrm{Al},{ }^{59} \mathrm{Ni}\right.$, ${ }^{63} \mathrm{Ni},{ }^{93} \mathrm{Zr},{ }^{93} \mathrm{Nb},{ }^{94} \mathrm{Nb},{ }^{151} \mathrm{Sm},{ }^{150} \mathrm{Eu},{ }^{152} \mathrm{Eu},{ }^{154} \mathrm{Eu},{ }^{166} \mathrm{Ho},{ }^{232} \mathrm{Th},{ }^{237} \mathrm{~Np},{ }^{238,239,240,241,242} \mathrm{Pu}$, $\left.{ }^{241,243} \mathrm{Am},{ }^{244} \mathrm{Cm}\right): 95-100 \%$ in glass 
- All uranium $\left({ }^{232-236,238} \mathrm{U}\right): 70-90 \%$ in glass

- ${ }^{36} \mathrm{Cl}$ and ${ }^{129} \mathrm{I}: 10-50 \%$ in glass

- ${ }^{40} \mathrm{~K},{ }^{41} \mathrm{Ca},{ }^{107} \mathrm{Pd},{ }^{113} \mathrm{Cd},{ }^{126} \mathrm{Sn}: 30-70 \%$ in glass

- ${ }^{90} \mathrm{Sr}$ and ${ }^{99} \mathrm{Tc}: 40-80 \%$ in glass

- ${ }^{121} \mathrm{Sn}: 20-60 \%$ in glass

- ${ }^{135}$ Cs: $20-70 \%$ in glass

- ${ }^{137} \mathrm{Cs}: 25-40 \%$ in glass

Glass Release Fraction: The fraction of glass released was based on the four categories developed as part of the Rainier Mesa HST analysis. The initial glass mass (700 tons per kiloton yield), temperature and associated cooling history will control the extent of glass dissolution. As a result, tests were categorized by yield, which correlates with glass volume and initial temperature. Yields were categorized as $<0.1 \mathrm{kt}, 0.1-1 \mathrm{kt}, 1-20 \mathrm{kt}$, and $>20 \mathrm{kt}$ based on reported yields or maximum announced yields identified in DOE/NV--209. Glass dissolution parameter uncertainties yielded percent glass dissolution ranges of 0.0013 to $0.11,0.0018$ to $0.14,0.0052$ to 0.67 , and 0.017 to $2.6 \%$, respectively, for the first 100 years of glass dissolution. Uncertainties were based on a log-triangular distribution. Details can be found in the Rainier Mesa HST report.

Cavity and Exchange Volume Porosity: The cavity and exchange volume porosity at each test were based on the average porosity of the HSU located at the working point. Bulking effects were not taken into account and parameter uncertainty was not included. Importantly, for this exercise, it was assumed that the entire porosity of the exchange volume was accessible to radionuclides. While this may not be the case in fractured exchange volumes outside the cavity at $\mathrm{t}_{0}$, simulations performed as part of the Rainier Mesa HST effort suggest that diffusion into the matrix within the exchange volume will occur relatively rapidly. Thus, this homogeneous distribution of radionuclides in the exchange volume may be more representative of $t+1$ year rather than a true time zero distribution.

Saturation: Saturation at each test was based on an estimate of the average saturation of the HGU located at the working point. Uncertainty in this parameter was not addressed. Saturations values were $0.25,0.45,0.45,0.8,0.8$, and 1.0 for tests located in AA, VTA, WTA, TCU, CA, GCU, respectively.

Kd by HSU: Radionuclide Kds were simulated based on the component additivity approach reported in a number of project documents (e.g., Carle et al., 2002, 2007; Tompson et al., 2005). Radionuclide-mineral sorption behavior is dependent on water chemistry. Thus, parameters were established based on four individual water chemistries (alluvium, tuff, carbonate, and granite water chemistries) that were calculated from well data at the NTS. Uncertainties in Kds were based solely on the uncertainty in surface complexation/ion exchange parameters and not the uncertainty in the water chemistry; surface complexation/ion exchange uncertainties are substantially larger than the effects of water chemistry. Kds at individual tests were based on the average mineralogy of the HSU at the working point location.

\section{C.3.6. Results}

Figure C.4 summarizes the distribution of initial activity of all radionuclides and all tests relative 
to their respective MCLs. It is a summary of 59,760 Monte Carlo realizations based on parameterization and uncertainties identified above. It is clear that many of the 43 radionuclides listed in Bowen et al. (2001) are unlikely to contribute to health risk since their concentrations fall well below their respective MCLs. At the 95\% confidence interval, only the following radionuclides may be found above $0.1 \mathrm{MCL}$ :

${ }^{3} \mathrm{H},{ }^{14} \mathrm{C},{ }^{36} \mathrm{Cl},{ }^{90} \mathrm{Sr},{ }^{99} \mathrm{Tc},{ }^{129} \mathrm{I},{ }^{137} \mathrm{Cs},{ }^{152} \mathrm{Eu},{ }^{154} \mathrm{Eu},{ }^{238} \mathrm{U}$, and ${ }^{238,239,240,241} \mathrm{Pu}$.

Of these, ${ }^{137} \mathrm{Cs},{ }^{152} \mathrm{Eu},{ }^{154} \mathrm{Eu}$, and ${ }^{241} \mathrm{Pu}$ will decay to below $0.1 \mathrm{MCL}$ before ${ }^{3} \mathrm{H}$. Thus, contamination by ${ }^{3} \mathrm{H}$ will always contribute more to the contaminant boundary calculation than these radionuclides. Based on this analysis, the contaminant boundary calculations in Yucca Flat can be limited further to the following radionuclides:

${ }^{3} \mathrm{H},{ }^{14} \mathrm{C},{ }^{36} \mathrm{Cl},{ }^{90} \mathrm{Sr},{ }^{99} \mathrm{Tc},{ }^{129} \mathrm{I},{ }^{238} \mathrm{U}$, and ${ }^{238,239,240} \mathrm{Pu}$.
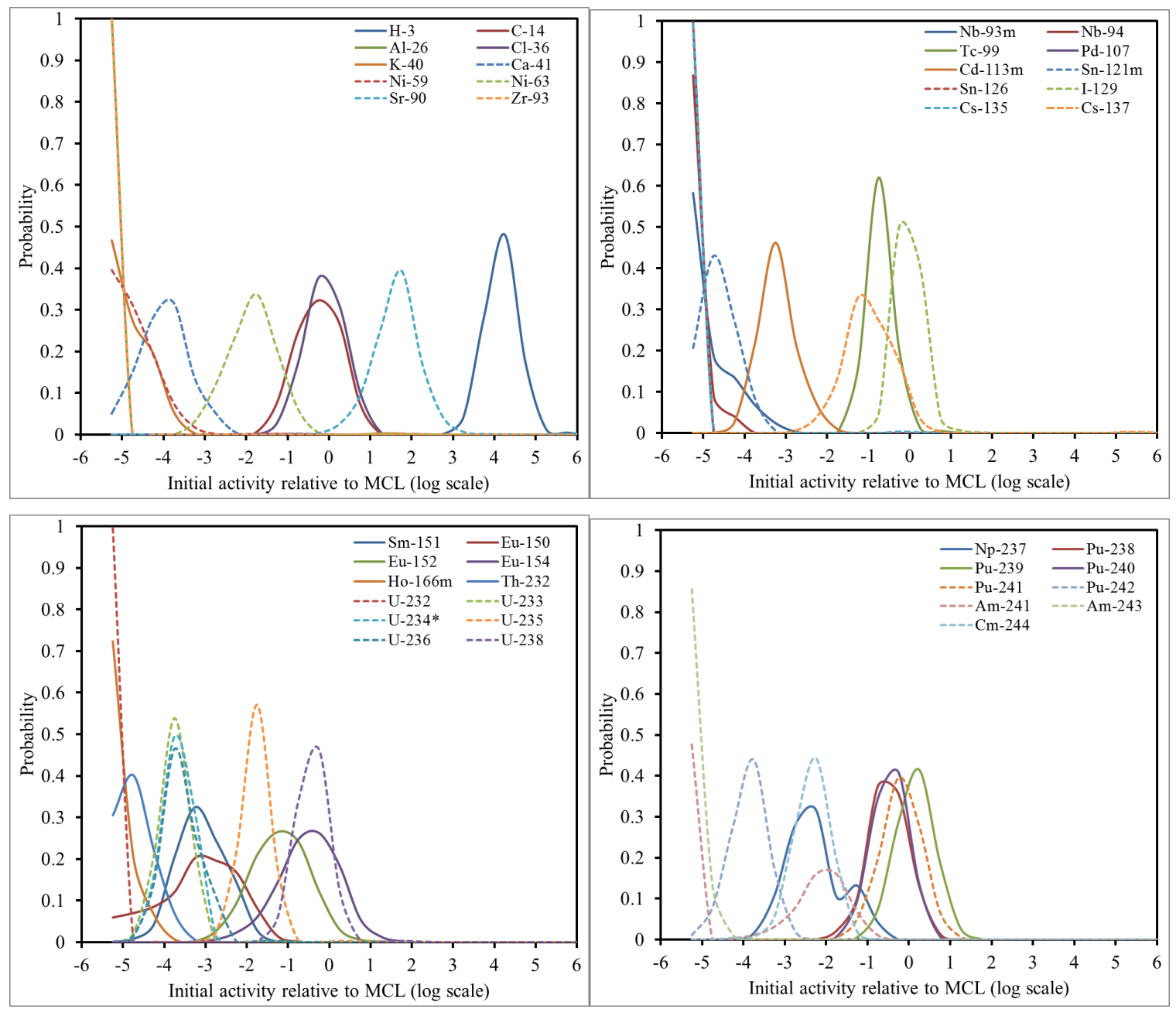

Figure C.4. Probability distributions of initial radionuclide concentrations (relative to MCLs) in all tests within the Yucca Flat CAU. 
However, given the unique nature of test and geochemical conditions in the three sub-regions of the CAU model (unsaturated zone, saturated tuff zone, and lower carbonate aquifer zone), radionuclide screening by sub-region is warranted. When the radionuclide screening is performed for tests within each of the 3 CAU sub-models separately, we find that the screening is dependent on the characteristics (e.g. mineralogy, saturation) of the sub-models (Table C.1). The major result is the inclusion of ${ }^{41} \mathrm{Ca},{ }^{63} \mathrm{Ni},{ }^{135} \mathrm{Cs},{ }^{137} \mathrm{Cs},{ }^{235} \mathrm{U}$, and ${ }^{237} \mathrm{~Np}$ to the LCA submodel and ${ }^{237} \mathrm{~Np}$ in the saturated zone sub-model. However, it should be noted that the ${ }^{41} \mathrm{Ca}$ and ${ }^{237} \mathrm{~Np} 95^{\text {th }}$ percentiles were very near the $0.1 \mathrm{MCL}$ limit in all sub-models. The primary reason for the increased number of relevant radionuclides in the LCA sub-model was the lower radionuclide $\mathrm{Kd}_{\mathrm{s}}$ predicted for carbonate rocks.

\section{C.3.7. Conclusions}

The screening analysis identified radionuclides that are likely to contribute to contaminant boundaries and provide a potential risk to the environment and the public. Of the 43 radionuclides listed in Bowen et al. (2001), only 10 radionuclides are likely to contribute to contaminant boundary calculations in all three sub-models. Five additional radionuclides may contribute to contaminant boundary calculations in some but not all sub-models.

Of the 16 radionuclides that may provide some contribution to contaminant boundary calculations, 5 are considered non-sorbing tracers $\left({ }^{3} \mathrm{H},{ }^{14} \mathrm{C},{ }^{36} \mathrm{Cl},{ }^{99} \mathrm{Tc}\right.$, and $\left.{ }^{129} \mathrm{I}\right)$. Of the remaining radionuclides, ${ }^{90} \mathrm{Sr},{ }^{135} \mathrm{Cs}$, and ${ }^{137} \mathrm{Cs}$ are very strongly sorbing in both alluvium and tuff. Thus, they are likely to be transported downstream only in the carbonate aquifer. Similarly, ${ }^{63} \mathrm{Ni}$ may be transported downstream at relevant concentrations only in the carbonate aquifer; its presence (or absence) has never been evaluated at the NNSS. The ${ }^{237} \mathrm{~Np} 95^{\text {th }}$ percentile concentration was found to be very near $0.1 \mathrm{MCL}$ in all sub-models. Thus, ${ }^{237} \mathrm{~Np}$ is unlikely to contribute significantly to contaminant boundary estimates. A recent survey of $\mathrm{Np}$ concentrations in "hot wells" from the NNSS indicates that Np concentrations are well below its MCL. ${ }^{235} \mathrm{U}$ and ${ }^{238} \mathrm{U}$ are identified as potentially contributing to contaminant boundaries. However, it should be noted that these uranium isotopes are primarily (but not entirely) of natural origin. Groundwater from clean wells at the NNSS commonly contains U concentrations within an order of magnitude of the U MCL $(30 \mathrm{ug} / \mathrm{L})$. The isotopes of $\mathrm{Pu}\left({ }^{238,239,240} \mathrm{Pu}\right)$ are strongly sorbing. However, the Pu inventory is very large and MCL is quite low, leading to the conclusion that it may contribute to contaminant boundary. In practice, $\mathrm{Pu}$ activities in groundwater have been detected above the MCL of $16 \mathrm{pCi} / \mathrm{L}$ at only two "hot well" locations (U$19 \mathrm{ad}$ and U-12t). At several other sites, $\mathrm{Pu}$ concentrations may be within an order of magnitude of the MCL. Pu is believed to migrate primarily associated with colloids. Thus, its transport velocity in fractured rock may be quite high. However, although there are not many wells located downstream of underground nuclear tests, the few that exist do not suggest Pu colloidfacilitated transport at concentrations above its MCL. Nevertheless, its contribution to contaminant boundary calculations cannot be eliminated using the screening methods described here.

\section{C.4. References}

Boardman, C.R. and J. Skrove (1966), Distribution in Fracture Permeability of a Granitic Rock Mass Following a Contained Nuclear Explosion. Journal of Petroleum Technology, May 619-623 
Borg, I. Y. (1973), Comparison of shock effects in granitic rock recovered from the Monique event Algeria and the Piledriver event, Nevada Test Site, Lawrence Livermore Laboratory, Livermore, CA, UCRL-51349

Borg, I. R., H. B. Levy, and L. D. Ramspott (1976), Information Pertinent to the Migration of Radionuclides in Ground Water at the Nevada Test Site, Part 1: Review and analysis of existing information, Lawrence Livermore National Laboratory, Livermore, CA, UCRL52078.

Bowen, S., D. L. Finnegan, J. L. Thompson, C. M. Miller, P. L. Baca, L. F. Olivas, C. G. Geoffrion, D. K. Smith, W. Goishi, B. K. Esser, J. W. Meadows, N. Namboodiri, J. F. Wild (2001), Nevada Test Site Radionuclide Inventory 1951-1992, Los Alamos National Laboratory, Los Alamos, NM, LA-13859-MS

Burkhard, N. R. and J. T. Rambo (1991), One Plausible Explanation For Groundwater Mounding, in Proc. Of the 6th Containment of Underground Nuclear Explosions, Lawrence Livermore National Laboratory, Livermore, CA, CONF-9109114, Vol. 2

Carle, S. F., M. Zavarin, and G.A. Pawloski (2002), Geostatistical Analysis of Spatial Variability of Mineral Abundance and Kd in Frenchman Flat, NTS, Alluvium, Lawrence Livermore National Laboratory, Livermore CA, UCRL-ID-150200

Carle, S. F., R. M. Maxwell, and G. A. Pawloski (2003), Impact of Test Heat on Groundwater Flow at Pahute Mesa, Nevada Test Site, Lawrence Livermore National Laboratory, Livermore, CA, UCRL-ID-152599

Carle, S. F., R. M. Maxwell, G. A. Pawloski, D. E. Shumaker, A. F. B. Tompson, and M. Zavarin (2007), Evaluation of the transient hydrologic source term for the Cambric underground nuclear test at Frenchman Flat, Nevada Test Site, Lawrence Livermore National Laboratory, Livermore, CA, UCRL-TR-226916.

Carle, S. F., M. Zavarin, Y. Sun, and G. A. Pawloski (2008), Evaluation of Hydrologic Source Term Processes for Underground Nuclear Tests in Yucca Flat, Nevada Test Site: Carbonate Tests, Lawrence Livermore National Laboratory, Livermore, CA, LLNL-TR403485

Essington, E.H. and E.J. Forslow. 1971. Distribution of radioactivity in and near the Rainier rubble chimney. Teledyne Isotopes, Nevada Operations, Las Vegas, NV: NVO-1229$180,81 \mathrm{p}$.

Germain, L. S., and J. S. Kahn (1968), Phenomenology and Containment of Underground Nuclear Explosions, Lawrence Livermore National Laboratory, Livermore, CA, UCRL50482

Halford, K. J., Laczniak, R. J. and D. L. Galloway (2005), Hydraulic characterization of overpressured tuffs in central Yucca Flat, Nevada Test Site, Nye County, Nevada, U.S. Geological Survey Scientific investigation report 2005-5211 
IAEA (International Atomic Energy Agency) (1998a), The Radiological Situation at the Atolls of Mururoa and Fangataufa, Technical Report, Volume 3: Inventory of radionuclides underground at the atolls, Vienna, Austria, IAEA-MFTR-3

IAEA (International Atomic Energy Agency) (1998b), The Radiological Situation at the Atolls of Mururoa and Fangataufa, Technical Report, Volume 4: Release to the biosphere if radionuclides from underground nuclear weapons tests at the atolls, Vienna, Austria, IAEA-MFTR-4.

IAEA (International Atomic Energy Agency) (1998c), The Radiological Situation at the Atolls of Mururoa and Fangataufa, Technical Report, Volume 6: Dose due to radioactive materials present in the environment or released form the atolls, Vienna, Austria, IAEAMFTR-6.

Knox, J. B., D. E. Rawson, and J. A. Krove (1965), Analysis of a groundwater anomaly created by an underground nuclear explosion, Journal of geophysical Research 70(4), 823-835.

McNab, W. W. (2008) Evaluation of Hydrologic Source Term Processes for Underground Nuclear Tests in Yucca Flat, Nevada Test Site: Unsaturated Tests and the Impact of Recharge, Lawrence Livermore National Laboratory, Livermore, CA, LLNL-TR-403360

OTA (Office of Technology Assessment) (1989), The Containment of Underground Explosions, United States Congress, Office of Technology Assessment, OTA-ISC-414.

Pawloski, G. A. (1999), Development of Phenomenological Models of Underground Nuclear Tests on Pahute Mesa, Nevada Test Site-BENHAM and TYBO, Lawrence Livermore National Laboratory, Livermore, CA, UCRL-ID-136003

Pawloski, G. A., A. F. B. Tompson, S.F. Carle, Eds. (2001), Evaluation of the Hydrologic Source Term from Undrground Nuclear Tests on Pahute Mesa at the Nevada Test Site: the Cheshire Test, Lawrence Livermore National Laboratory, Livermore, CA, UCRL-ID147023.

Pawloski, G. A., G. WoldeGabriel, and I. Farnham (2005), Categorization of Underground Nuclear Tests on Yucca Flat and Climax Mine, Nevada Test Site, for use in Radionuclide Transport Models, Lawrence Livermore National Laboratory, Livermore, CA, UCRLTR-235536.

Pawloski, G. A., A. F. B. Tompson, S. F. Carle, R. L. Detwiler, Q. Hu, S. Kollet, R.M. Maxwell, W.W. McNab, S. K. Roberts, D. E. Shumaker, Y. Sun, and M. Zavarin (2009), Evaluation of Hydrologic Source Term Processes for Underground Nuclear Tests in Yucca Flat, Nevada Test Site: Introduction and Executive Summary, Lawrence Livermore National Laboratory, Livermore, CA, LLNL-TR-4003428

Rose, T. P., Q. Hu, P. Zhao, C.L. Conrado, R. Dickerson, G.F. Eaton, A.B. Kersting, J.E. Moran, G. Nimz, B.A. Powell, E.C. Ramon, F.J. Ryerson, R.W. Williams, P.T. Wooddy, and M. Zavarin (2011) Radionuclide Partitioning in an Underground Nuclear Test Cavity Lawrence Livermore National Laboratory, Livermore, CA, LLNL-TR-409817 
Smith, D. K., D.L. Finnegan, and S. M. Bowen (2003), An inventory of long-lived radionuclides residual from underground nuclear testing at the Nevada test site, 1951-1992, Journal of Environmental Radioactivity (67) 35-51

Tompson, A. F. B., R. M. Maxwell, S. F. Carle, M. Zavarin, G. A. Pawloski, and D. E. Shumaker (2005), Evaluation of the Non-Transient Hydrologic Source Term from the CAMBRIC Underground Nuclear Test in Frenchman Flat, Nevada Test Site, Lawrence Livermore National Laboratory, Livermore, CA, UCRL-TR-217191.

Tompson, A. F. B., ed., R. M. Maxwell, R. L. Detwiler, Q. Hu, S. Kollet, and S. K. Roberts (2008) Evaluation of Hydrologic Source Term Processes for Underground Nuclear Tests in Yucca Flat, Nevada Test Site: Saturated Tests, Lawrence Livermore National Laboratory, Livermore, CA, LLNL-TR-4003429

Tompson, A. F. B., ed., M. Zavarin, W. W. McNab, S. F. Carle, D. E. Shumaker, C. Lu, Y. Sun, G. A. Pawloski, Q. Hu, and S. K. Roberts (2011) Hydrologic Source Term Processes and Models for Underground Nuclear Tests at Rainier Mesa and Shoshone Mountain, Nevada Test Site, Lawrence Livermore National Laboratory, Livermore, CA, LLNL-TR-4003429 DRAFT

USDOE (U.S. Department of Energy) (2000), United States Nuclear Tests, July 1945 through September 1992, USDOE, Nevada Operations Office, Las Vegas, NV, DOE/NV-209 Rev 15.

Vincent, P., S. Larsen, D. Galloway, R. J. Laczniak, W. R. Walter, W. Foxall, and J. J. Zucca (2003), New signatures of underground nuclear tests revealed by satellite, Geophysical Research Letters, 30(22), 2141, doi:10.1029/2003GL018179

Wadman R. E. and D. Richards D. (1961), Postshot geologic studies of excavations below Rainier Ground Zero, Lawrence Livermore National Laboratory, Livermore, CA, UCRL 6586

Wolfsberg, A., Ed. (2006), Analysis and evaluation of elevated groundwater heads and their impact on flow and solute transport in the Tuff Pile: Areas 3, 4 and 7 of the Nevada Test Site, Nye County, Nevada, Los Alamos National Laboratory, Los Alamos, NM, Draft Report, October. 
